\title{
AN INTERACTIVE COMPUTER-BASED CIRCULATION SYSTEM FOR NORTHWESTERN UNIVERSITY: THE LIBRARY PUTS IT TO WORK
}

Velma VENEZIANO: Systems Analyst, Northwestern University Library, Evanston, Illinois

Northwestern University Library's on-line circulation system has resulted in dramatic changes in practices and procedures in the Circulation Services Section. After a hectic period of implementation, the staff soon began to adjust to the system. Over the past year and a half, they have devised ways to use the system to maximum advantage, so that manual and machine systems now mesh in close harmony. Freed from time-consuming clerical chores, the staff have been challenged to use their released time to best advantage, with the result that the "service" in "Circulation Services" is much closer to being a reality.

The transition from a manual to an automated system is never easy. Northwestern University Library's experience with an automated circulation system was no exception. The first three months of operation were especially harrowing; there were times when only the realization that the bridges back to the old system were burned kept the staff plugging away with a system which often seemed in imminent danger of collapse. That they survived this period is a tribute to their persistence and optimism as well as to the merit of the system.

The impressive array of obstacles was offset by a number of positive factors. Even though there were mechanical problems with terminals, the on-line computer programs worked flawlessly from the first. The climate for change was favorable. The automation project had the complete support of library administration; the head of circulation services, although new to the department and untrained in automation, was completely committed to the system and was able to transmit his enthusiasm to his staff. 
Within three months, the systems analyst, who had been available for advice and trouble-shooting, began to fade from the scene. Only an occasional minor refinement is now necessary. Maintenance problems, both in programs and procedures, are minimal. Basically the system has proved itself workable.

In a previous paper by Dr. James S. Aagaard (JOLA, Mar. 1972), the development of the system is traced and the system is described in terms of its logical design, program, and hardware components. The present paper will describe how the system operates in the library environment. The system accomplishes the traditional library tasks connected with circulation, but the methods used have changed radically. The development of effective procedures must in large part be credited to the circulation staff. These procedures have in a real sense spelled the difference between an adequate system and a good one. It is these procedures on which we will concentrate.

The author wishes to thank the head of circulation services, Rolf Erickson, and his assistants, Mrs. Eleanor Pederson and Mrs. Lillian Hagerty, for supplying the information to bring her up-to-date on procedures as they have evolved over the past three years.

\section{BOOK IDENTIFICATION}

Almost 100 percent of the 900,000 books in the main library's circulation collection contain punched cards. Accurately punched book cards, available in all books, can make the difference between success and failure of a circulation system.

The book cards contain only the call number and location code. There is no doubt that, if conversion funds had been less limited, we might have elected to capture author/title data. However an analysis of the amount of data which could be carried on an 80-column card, added to the fact that this would quadruple the cost, led to the decision to omit author/title. As a result, key punch costs were exceptionally low-1.1 cent per card. In spite of our fears, the complaints by users because overdue and other notices do not contain author/title have been surprisingly few.

Cards for new books are, with a few exceptions, produced automatically as output from the Technical Services Module. All book cards are also on magnetic tape and constitute a physical inventory of the entire circulating collection, which is updated at intervals and listed.

\section{USER IDENTIFICATION}

The system requires a unique numeric identification number for each borrower. For faculty and Evanston campus students, this is their social security number; for special users it is a five-digit number assigned by the library from a list of sequential numbers. The number is supplemented by a one-digit code which identifies the type of user. 
The university's Division of Student Finance has responsibility for issuance of punched plastic badges for students. Each spring at preregistration time, data are gathered and pictures taken for students planning to return to the university in the fall. Badges are ready for distribution as soon as school opens.

For incoming freshmen, transfers, and returnees, data are gathered and badges punched at registration time in the fall. A temporary paper badge is used during the several weeks required for badge preparation.

An outside contractor prepares and punches the badges. There were initial problems with the accuracy of punching but these have been resolved. The library now has a small IBM 015 badge punch, which it uses for punching special user badges and badges for carrel holders. Student badges are valid for one year. The user code is changed each year to prevent use of an expired badge. Faculty and staff badges are issued by the Personnel Department of the University, and are good for three years. These are also produced by an outside firm.

\section{BOOK SECURITY}

Exit guards examine all books taken from the library to ensure that they are properly charged. The call number on the book and on the date-due slip are compared; the user number on the date-due slip and the user's badge are compared. This need not be a character-by-character comparison. A few selected characters will suffice.

Student badges contain their pictures, which should bear at least a resemblance to the holder of the badge. Initially, students were not required to show their badges. After a rash of book thefts resulting from the use of lost or stolen badges, this policy was changed. The book-check routine sometimes slows exit from the building during peak periods; however it is considered a necessary security measure.

The problem of lost badges is a serious one. Users tend to leave badges in the terminals. Usually such badges are turned in at the main circulation desk by the next user; the owner is notified to come in and pick it up. If a student loses his badge, he must report it to the circulation desk as soon as possible. He is issued a special user badge, and the computer center is notified to "block" his regular user number. If someone then tries to use the badge, an "unprocessed" message will appear in lieu of a valid date-due slip.

The problem is timing. "Blocking" is done only once a day. A determined thief can charge out a considerable number of books before the number can be blocked. For this reason, a check of the photograph on the badge is important. The maximum number of user numbers which can be blocked is fifty. Fortunately, except for faculty/staff badges which are good for three years, student badges automatically become invalid at the end of each school year, and special user badges expire at the end of each quarter.

Behind the decision to go on-line was the belief that a university library, 
to effectively serve its patrons, needs to be able to determine the status of a book without delay.

All books which are not in their places on the shelves as indicated by the card catalog are, in theory, reflected in the computer circulation file. Out of a circulating collection of 900,000 items, the number of records in the file at any one time will range from 30,000 to 60,000 . This includes books temporarily located in the Reserve Room, books being bound, and books which have been sent to the catalog department. It also includes books which are lost or missing but which have not yet been withdrawn from the catalog.

A single 2740 typewriter terminal, located at the main circulation desk, is used for inquiry into the circulation file. A library user, having obtained the call number of a book from the catalog, looks for it in the stacks. If he is unable to find it, he inquires at the terminal. The operator enters a command "search," followed by the abbreviated call number of the book (the key). If one or more records with this key are in the file, the file address, plus the balance of the call number (the key extension), are typed back from the computer for each such record.

If one of the listed records is the desired one, the operator then asks for a display of the record. The display includes the due date, type of charge, user number, and, if there is one, the saver number.

The ability to use an abbreviated call number to access the file has proved invaluable. The operator can in effect "browse" among all the various editions, copies, and volumes of a particular book which are in circulation. The technique also facilitates finding a record, such as a volume in a serial, where the format is often quite variable, and not always obvious from the call slip supplied by the user.

If a large number of books all with the same key are in the file, there is sometimes a considerable wait while the typewriter types out the addresses and key extensions for all the records. Once such a listing begins, there is no way at present to cut it off in mid-point. This is a minor inconvenience; it could be remedied quite easily if computer core were not such a precious commodity.

The single 2740 terminal is heavily used and plans are under way to substitute a cathode ray tube in the near future.

\section{BOOK LOCATE PROCEDURES}

If a search on the 2740 terminal reveals that a book is not in circulation, the individual may ask that it be "located." A form is filled out and the book is searched nightly in the stacks. (It is also again searched in the 2740 since it may have been charged out to another user after the inquiry.)

If it is found, it is brought down and placed on the "save" shelf, and the inquirer is notified that it is available.

If it is not found, the form is held for two weeks and searched again, both in the 2740 and the stacks. If it is not found on the second search, it is 
entered into the file as a "missing book." The circulation section has found that entering missing books into the file as soon as possible saves them time, because a search for a single book is often duplicated needlessly for a number of different individuals.

\section{SAVE PROCEDURES}

When a user is informed that a book is in the circulation file, he may ask that it be called in for him, provided it is not on loan to the Reserve Koom and provided it is not already "saved" for someone else. The 2740 operator calls in the record and adds the saver's identification number to the record.

Each weekday morning, "book needed notices" are sent over from the computer center for books "saved" since the last notice run. The notices are stuffed in window envelopes and mailed.

Even though the number of saves is small, in relation to the total number of books charged out, this feature has contributed to the library's and the user's satisfaction with the system.

Initially there was some consideration given to providing for multiple saves on the same book. A study of the frequency of multiple saves indicated that the increased system complexity did not warrant it. Moreover, a student usually cannot wait too long for his turn at a book. A better solution in a university library is either to buy more copies or place high demand books in the Reserve Room, or both.

The standard loan period is four weeks. A save on a book causes the due date to be recalculated either to two weeks, or to five days from the date of the save, whichever is later. This variable loan period increases the number of users who can use a book in high demand, without inconveniencing the user of a book which no one else needs.

To succeed, such a call-in policy must be backed with enough force to ensure that a called-in book is returned promptly. If a book is returned after the revised due date, the user incurs a penalty fine of $\$ 1.00$ per day in addition to the regular 10 cents per day fine. Expired call-ins result in a weekly computer-generated reminder.

When a book which is saved is discharged, the terminal printer issues a message to this effect, and the book can be placed on the "save" shelf instead of being sent to the stacks. Each night "book available notices" are produced for all such books discharged since the last notice run. The first copy of the notice is mailed to the saver; the second part is inserted in the book. The saver is given five weekdays to pick up the book.

\section{BOOK CHARGES}

\section{Self-service Charges}

During the regular school year, from 1000 to 1200 books per day are charged out through the system. Most of these charges are processed by the users, on the self-service terminals. 
A basic objective in the design of the system was to make it easy for the user to charge out books. Initially it was planned to have manned chargeout terminals. However, as the design of the system progressed, it became evident that the vast bulk of charge-out transactions would consist of three simple steps: (1) insert the user badge, (2) insert the book card, and (3) tear off the date-due slip. The idea arose: If the procedure was so simple, why not let the user himself do it, thus saving the cost of terminal operators? There was some concern over user reaction, but it was decided it was worth the risk.

A simple set of illustrated instructions is attached to the terminal. Since the terminal will not accept badges or book cards unless they are inserted in the proper direction, the user soon gets the idea. The terminal will also refuse a seriously off-punched badge or book card.

If everything is done properly, the printer produces a date-due slip containing the user number, the book call number, and the date due. This is detached and placed in the book pocket.

If, instead of a valid date-due slip, the user receives a slip from the printer containing the word "UNPROCESSED," he is instructed to take all materials to the main circulation desk. This condition will occur if the individual tries to take out a book which is already charged out (perhaps to the Reserve Room or a carrel). It also happens if the badge or book card has fewer than the required complement of characters or if the user code on the badge has expired. It also happens if the user's number has been "blocked."

Although readers had no difficulty mastering the technique of using the 1031 badge/card reader, the 1033 printer was another story. Despite the printed and illustrated injunction to "tear the slip forward," the users insisted on pulling the paper upward. The result-the continuous roll of paper would start to skew and the paper would eventually jam.

To alleviate the skewing problem, we had pin-feed platens installed in the typewriters. These prevented the skew, but the upward pull on the paper caused the pin-feed holes to tear and get out of alignment with the pins. The result-a paper jam. The IBM field engineers valiantly tried to overcome the condition but to no avail. IBM was unwilling to make any major modification of the paper feed mechanism, and no amount of argument that such an improvement would increase their sales to other libraries had any effect.

In desperation, the library finally took its problem to the Physics Shop in Northwestern University's Technological Institute. The technicians there designed and built a hooded feed to channel the paper upward and forward at the desired angle. A hand-actuated knife blade was installed to cut and dispense the ticket-type slip.

In spite of these heroic efforts, paper jams still occur with enough frequency to be annoying. Since the terminals are isolated in the stacks, a jam often goes undetected until a user comes down to the main circulation desk 
with a complaint. For this reason, we have plans to install a "ticket printer," which will automatically cut and eject a ticket with no user intervention.

Unlike the 1033 printer, there has been very little down-time due to malfunctioning of the 1031 badge/card reader.

Due to their isolation on the stack floors, there was some early tampering with the terminals. Now that the newness has worn off, the terminals seem to have lost their appeal to pranksters, except that the photographs used to illustrate procedures have a way of disappearing.

Everything taken into consideration, the self-service concept has proved completely feasible. It saves staff time and user time. The time required to charge out a book ranges from ten to fifteen seconds.

\section{Carrel Charges}

Each quarter, the circulation section assigns carrels to individuals, mostly graduate students and faculty. Carrel holders may charge out books for use in their carrels. A special loan code is entered which results in the date-due slip bearing the word "CARREL." The user cannot take these books from the building.

Carrel charges are subject to call-in after two weeks but are not subject to fines. At the end of each quarter, unless the carrel has been reassigned to the same individual, any remaining books in the carrel are picked up and discharged. Once a quarter, the carrel user receives a computer-printed list of books charged to his carrel.

Carrel holders tend to charge large numbers of books. For saving time on their part and on the part of staff, plastic badges are issued. These will contain the carrel number, the carrel code, and an expiration date. Carrel holders may then use the self-service terminals in the stacks.

\section{Charges to the Reserve Room}

The Reserve Room does not use the circulation system for charges to individuals, since the loan period is so limited. However the circulation file contains a record of all books located in the Reserve Room.

When a book is charged to the Reserve Room, the identification number of the Reserve Room is entered in the 1031 slides, together with a loan code indicating an indefinite loan period. Processing of large batches of books is speeded up by suppressing the printing of date-due slips for all intralibrary charges.

After charging, the punched book card is removed and held until the book is ready to be returned to the stacks, at which time the book is discharged in the regular manner.

If a book needed for reserve cannot be found in the stacks, it is searched in the 2740 terminal. If it is in the file, a save is placed on the record which generates a book-needed notice. The user is given five days to return the book. When the book is returned and discharged, a printer message alerts 
the discharger, who places the book on the shelf for pick-up by the Reserve Room.

If the book is not in the file, it goes through the "book locate procedure," after which, if it is not found, it is processed as a "missing" book. If such a missing book turns up, it can be immediately identified as needed by the Reserve Room.

A quarterly listing, in call number order, is received from the computer center for all books charged out to the Reserve Room. This list serves as the Reserve Room's shelf list.

\section{Bindery Charges}

If a book is found to be in bad condition, it is set aside for a bindery decision. If it is beyond repair, it is charged out to the Catalog Department to be replaced or withdrawn. (After it is withdrawn it is deleted from the file.) If it can be repaired in-house, it is charged out to the mending section. If it must be sent to a commercial binder, it is charged to the bindery.

The bindery section prepares an extra copy of the bindery ticket for all periodicals and unbound items, which it sends to the bindery. This ticket is used to keypunch a book card, which is then used to charge the book to the bindery. Whenever a book is back from mending or binding, it is discharged before sending to the stacks.

\section{Renewals}

All renewals are processed at the main circulation desk. The procedure is identical to a regular charge except that a slide on the terminal is set to "renew." The new date-due slip will contain the phrase "RENEW TO."

In theory, the self-service terminals could be used for renewals. In practice, unless elaborate precautions were taken, a user could renew a book before it became due and then return it for discharge, leaving one slip in the book and keeping the other. After the book reached the stacks, the user could insert the extra date-due slip and walk out undetected. As protection against this, the original date-due slip must be in the book when it is renewed.

Phone renewals are not accepted. However, if the user mails or brings in his date-due slips, the renewal is processed on the 2740 .

In the renewal of a book via the 2740 , the record is called in and modified to change the date due and enter the correct renewal code. The original date due slip is stamped with the new date and the phrase "RENEWED." The slip is mailed to the user.

Although record modification via the $2 \pi 40$ is a valuable and necessary feature, it must be used with discretion, since the generalized file management system governing the 2740 does not have the controls contained in the circulation-specific portions of the program which handle data from the 1030 's; for example, automatic calculation of date due, rejection of renewals on saved books, validation of codes, etc. 


\section{BOOK DISCHARGE}

Returned books are left in book bins, one inside the building and one outside.

It became very evident during the implementation phase of the system that the success of the system depended on a thorough screening before discharge for purposes of detecting and deflecting potential problems before they got to the discharge terminal.

Books are first placed on dated trucks and then screened.

\section{Books without Punched Book Cards}

If the punched book card is missing, there will usually be a hand-written date slip in the book (the result of a manual charge). The screener pulls the matching book card from the "book-cards-pending" file. (After a manual charge, book cards are punched and filed in this file to avait the return of the book. ) The book is then ready for regular discharge. If there is no book card waiting, the book must be held until a card is ready. This is done to avoid the charge being made after the discharge.

\section{Books with Incorrect Book Cards}

All book cards are checked to see that they match the call number on the book pocket. Sometimes cards get switched between two books by the user when he charges them; sometimes the error was made when the card was originally matched with the book.

If a book is found to contain an incorrect card, sometimes the correct card will be found in the "cards-pending" file. If so, it is pulled and inserted and the book sent for regular discharge. (The incorrect card becomes a "snag".)

If the correct card is not found, the record is searched in the 2740 under both call numbers (the one on the card and the one on the book).

If the record is under both call numbers, the record which matches the book is deleted; the book is sent to keypunching; the unmatched book card is filed in the "cards-pending" file to await the return of the book which matches it.

If the record is found under only one of the two call numbers, it is deleted. The book is sent to keypunching; the unmatched book card becomes a "snag."

"Snag" cards will be searched in the shelf list and, if they represent valid books, will be searched in the stacks. This is done to determine if a matching book can be found.

\section{Books without Date Due Slips}

The presence of a date due slip in a book usually indicates that the book should be in the circulation file. A slip will be missing if the user never charged it out or if he lost (or removed) the slip after charging it out.

Such books are searched on the 2740. If no record is found, the book is sent to the stacks. If a record is found, it is deleted. However, we wish to 
guard against the user returning to insert the date due slip and walk out with it; thus, the book is not sent to the stacks until the date due is past.

\section{Regular 1031 Discharges}

The speed and accuracy of discharge are features which have contributed much to the success of the system.

A book with a date-due slip and book card which matches the book go to the 1030 terminal at the main circulation desk for discharge. One slide is set to either "fine paid" or "fine not paid." (If the user paid a fine at the time he returned the book, a "fine paid" flag will be in the book.)

Another slide is set to "book returned today," or "book returned yesterday," or "book returned prior to yesterday." If the last condition applies, the date of return is also set in the slides.

Once set, these slides need not be reset until there is a change of date or fine condition. For minimizing the resetting of slides, books are segregated into groups all of the same type.

Discharging is the essence of simplicity. The book card is inserted in the reader; it feeds down and out and is replaced in the book. The date-due slip is discarded and the book is ready for shelving.

For the purpose of speeding up discharge, no printer message is received unless there is an error (record not in file), or unless the book has a save on it, or is a "found" lost book.

One operator can discharge five to six books per minute. Books are almost always discharged within one day of return and usually within three or four hours. If a large number of books should pile up after a period of computer down-time (fortunately rare), a massive discharge campaign is launched. Two operators, working together on the terminal, can discharge books at the rate of one every eight seconds.

If at the time of discharge a "save" message appears on the printer, the book is placed on the save shelf instead of being sent to the stacks. If a lost book is "found," the message alerts the operator to send the book to the staff member in charge of lost and missing books.

If a message is received to the effect that no record exists in the file, the book is routed to the 2740 operator.

Occasionally the 1031 terminal will misread a card, usually due to improper folding. If a card is folded outside the punched area it causes no trouble. Unfortunately, some of the original cards were folded in the middle which sometimes results in a punch being missed. This, in some cases, cannot be detected by the computer program.

If the error resulted from a mis-read card, the terminal operator can usually determine, from the date-due slip and the error-message slip, the key under which the record exists. The record is deleted and the book sent to have a replacement card punched.

An occasional cause of the "record-not-in-file" condition results when the charge was processed on the Standard Register punch (the mechanized 
back-up system). This punch has a disconcerting habit of dropping a punch from badges which have a slight defect. There is no warning when this happens, and the error is often not detected until the transaction is later processed through the 1030 terminal. Since it is impossible to identify the user with certainty, such cards are simply discarded without processing on the assumption that most users are basically honest and will return the book. The 2740 operator, seeing a date-due slip with a short identification number, is safe in assuming the record never got in the file.

Sometimes the "record-not-in-file" condition is the result of a discharger absent-mindedly discharging a book twice. If the 2740 operator cannot find a record, she gives up and sends the book to the stacks.

During the early days of operation, when much of the charging was being done on the source record punch, the "record-not-in-file" condition was often due to the book being "discharged" before the charge was processed. The very small amount of down-time now, coupled with careful scheduling when it does occur, has almost eliminated this source of error.

\section{OVERDUE BOOKS}

Overdue notices for students and special individual users are prepared once a week. To avoid sending out large numbers of notices for books only a few days overdue, an overdue notice is prepared only if the book is at least four days overdue.

A second notice is prepared two weeks after the first; a third and final notice is prepared two weeks after that. If there is no response to the final notice within two weeks, a "delinquent" notice is prepared which is not sent out but is used to prepare a bill for a "lost" book. The overdue-notice run also produces reminders of expired call-ins.

\section{FINES AND FINE COLLECTION}

Faculty and staff are fine-exempt. Students and other individual users pay a 10 cents per day fine for books overdue more than three days. In addition, if a reader does not respond to a call-in by the revised due date, he is charged a $\$ 1.00$ per day penalty fine.

A user may elect to pay a fine on an overdue book at the time he returns it, in which case a "fine-paid" flag is inserted to alert the discharger to set the proper slide. No fine notice will result if this slide is set.

For all other books returned late, fine notices are computer-prepared each weekday. These are on four-part forms; one copy is inserted in a window envelope and mailed; the other three parts are filed alphabetically by name.

When the user pays his fine, the extra slips are discarded. If the fine is not paid in a reasonable period, one of the extra copies is sent as a follow-up notice. If no response to the follow-up is received, and if the total bill exceeds $\$ 3.00$, the bill is sent to the Department of Student Finance for collection. 
Sometimes the receiver of an overdue notice will come in to report that he (1) returned the book, (2) lost it, or (3) never had it. In such cases the book is searched in the 2740 because the book may have been returned since the overdue notice was prepared.

If the record is still in the file, the item is verified in the shelf list. In some instances an incorrectly punched card is responsible for the item not being properly discharged. If a call number on a notice cannot be found in the shelf list, there is no alternative except to delete the record and absolve the reader of responsibility.

If the call number on the notice represents a valid book, it is searched in the stacks and if found, is brought down and discharged, with a resultant fine notice. When the book cannot be found, the reader is usually held responsible for it, unless it was a case of a lost badge which was reported promptly, in which case the library is usually lenient. If no lost badge was involved, the book is processed as a "lost" book and the user is billed. A book is also considered lost (and the user billed) if the user does not respond to three overdue notices.

Weekly overdue notices are not prepared for faculty. Instead a once-aquarter computer-produced memo is prepared informing the individual of the books charged to him. He is asked to return them or notify the library by carbon copy of the list that he wishes to retain them. If a faculty member does not return the list, the library calls in the books individually.

As part of this quarterly memo run, listings of books charged to carrels and to departments (reserve room, bindery, cataloging, etc.) are produced. These listings have proved very valuable in maintaining control over books charged out on a long-term basis.

\section{LOST BOOKS}

When a book is determined to be "lost," a duplicate book card is prepared. The history of the loss, including the name and address of the individual involved, is entered on the card. If the reader is held responsible, the book is priced and a bill is prepared.

The original record is left in the file until all the documents are prepared. Then it is deleted via the 2740 , and a duplicate card is immediately used to charge the book out to the "lost" category. The duplicate card is then filed in the "lost/missing" file, by call number.

Another category of books is known as "missing." These are books which, although not charged out to anyone, cannot be found in the stacks. A duplicate card is prepared and used to charge the item out to the "missing" category. The card is filed in the "lost/missing" file.

Once a quarter, a computer-produced listing of lost/missing books is received. Using this list, the stacks can be searched to see if the books have turned up. The list of books lost or missing for more than two years it turned over to the Catalog Department for withdrawal. After official withdrawal, the record will be deleted from the file. 
The fact that all lost/missing books are reflected in the file has aided in detecting them if they turn up. If such a book is discharged, a printed message alerts the operator who routes the book to the person in charge of lost/missing books. The duplicate card is then pulled from the lost/missing file. Since the card contains the name of the responsible individual, it is possible to trace down the original bill in case an adjustment is necessary.

Lost/missing books also turn up if someone tries to charge them out. The "UNPROCESSED" message which is printed instead of a date-due slip will usually cause the reader to bring the book to the main circulation desk where the proper action can be taken to reinstate it in the collection.

\section{MANUAL CHARGES}

The system had to be designed so a book could be charged out even if it did not have a punched book card. Such books are brought to the main circulation desk where a two-part form is hand-prepared. One part becomes a date-due slip; the other part goes to keypunching. A composite card containing the call number, the user number, and the loan code is punched, which is then fed through the 1030 to create a charge record.

Also keypunched at this time is a regular book card, which is filed in the "cards-pending" file to await the return of the book.

Such manual charges are very unsatisfactory. Call numbers and identification numbers are often illegible or miscopied. Keypunch errors are not uncommon. Care must be taken that the composite cards are processed through the 1030 before the book is returned for discharge. Fortunately, books without cards are now a rarity.

\section{MECHANIZED CHARGES}

Although the amount of computer down-time is very slight, some means had to be devised to charge out books during such periods. The manual charge procedure could have been used; however the high error rate in copying and punching, coupled with the delay in keypunching any substantial volume of cards, caused us to reject this as a back-up system.

A Standard Register Source Record Punch is used. This punch reads the badge and book card and transfers the data, plus data from a series of internal slides, to produce a printed date-due slip and a punched composite card. When the computer comes back on, the composite card is fed through the 1031 to set up the charge record.

Since only one machine can be justified from a cost standpoint, the process of charging books out in this fashion is slow. Long lines of people often form, waiting for service. Resetting the internal slides between one loan code and another is awkward and error-prone. The machine is extremely sensitive to badge quality and often misses a punch.

However, as with manual charges, the most significant disadvantage is that charges are made "blind." There is no way to determine whether a book is not already in the file, or, if it is being renewed, that it has a save 
on it. The user's number may be one of those "blocked" from use; this fact is not detected until it is too late.

As with manual charges, care must be taken that all such mechanized charges are processed through the 1030 before any discharging is done.

In spite of its defects, the Source Record Punch has proved useful as a system back-up. The error rate in transfer, while higher than on the 1030, is significantly less than the error rate of manually prepared and keypunched charges. Although slow, records get into the file much faster than if they had to be keypunched.

\section{THE IMPACT OF THE SYSTEM ON THE LIBRARY}

The new system has had a profound impact on the operation of the circulation services section, but other departments have also been affected, particularly Technical Services.

Tighter control of cataloging is now maintained. No longer is it feasible for small uncataloged collections or collections with off-beat cataloging to exist in virtual isolation from the rest of the library. Regulations as to depth of classification have had to be adopted; the formation of the Cutter number and work letters must be carefully regulated; the assignment of volume and edition numbers must be uniform. Location symbols require careful control; no longer can books be casually passed from one collection to another without official transfer. Withdrawal of lost and missing books must be systematically performed.

The system gives maximum flexibility-books may circulate on LC class numbers or document numbers as well as on a Dewey number. Ways of handling non-standard Cutter numbers and work letters have been improvised. At the same time, the system operates to prevent unnecessary haphazard and shortsighted practices.

Within the circulation services section, the computerization of circulation has not resulted in fewer personnel; it has, however, resulted in the same number of staff members being able to handle a much larger volume of circulation and to handle it more efficiently. In addition, Circulation Services has taken on a number of tasks which in the past were either not its responsibility or, if they were, were given only perfunctory attention.

A comprehensive inventory of the entire collection of $1,200,000$ books in the main library is in progress. Errors both on books and in the catalog are being corrected. The physical condition of the collection is being attended to. The content and quality of the collection are receiving increased attention. Incomplete serial holdings are being brought to light for possible acquisition. Books in the stacks which are candidates for inclusion in the "Special Collections" Department are being detected.

So far as circulation proper is concerned, it can be said without reservation that the system saves a great deal of clerical effort. Staff time spent in charging out books is very small. Discharging an average day's books 
requires three or four man-hours. Filing has almost disappeared as has most of the typing formerly required.

A 2740 operator is required for inquiry and processing of mail renewals for the better part of the day and evening. The collection and follow-up on fines and bills is still a time-consuming job, although the extra forms available for follow-up have supplied some relief.

The system is not perfect. There are certain improvements-such as on-line validation of users and automatic regulation of loan privilegeswhich would be made if the time and money were available for them. However, considering the modest cost of developing and operating the system, the imperfections are bearable.

Not the least of the benefits derived from the system is a somewhat intangible one. The role of the circulation librarian, and that of his staff, has changed. No longer are they chained to mountains of cards which, as soon as they are filed, must be unfiled. Staff members have been challenged to use their released time to the best advantage. Much thought and ingenuity has gone into setting up procedures to achieve maximum efficiency and accuracy. For the first time, perfection is seen as an attainable goal. Each day the staff develops more sophistication and gets a step closer to that goal.

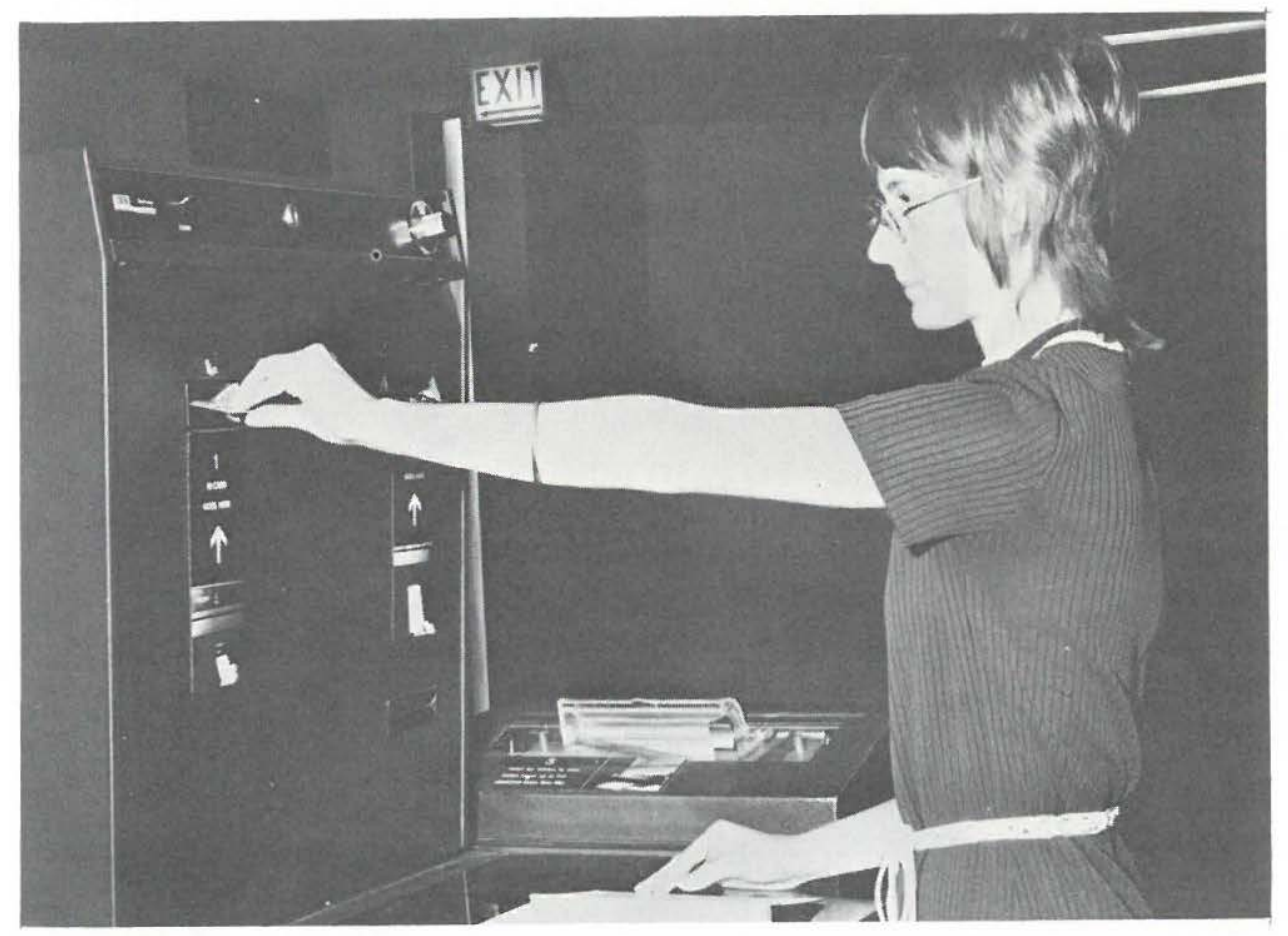

Figure 1. User inserts identification badge and punched book card in self-service circulation terminal. 
116 Journal of Library Automation Vol. 5/2 June, 1972

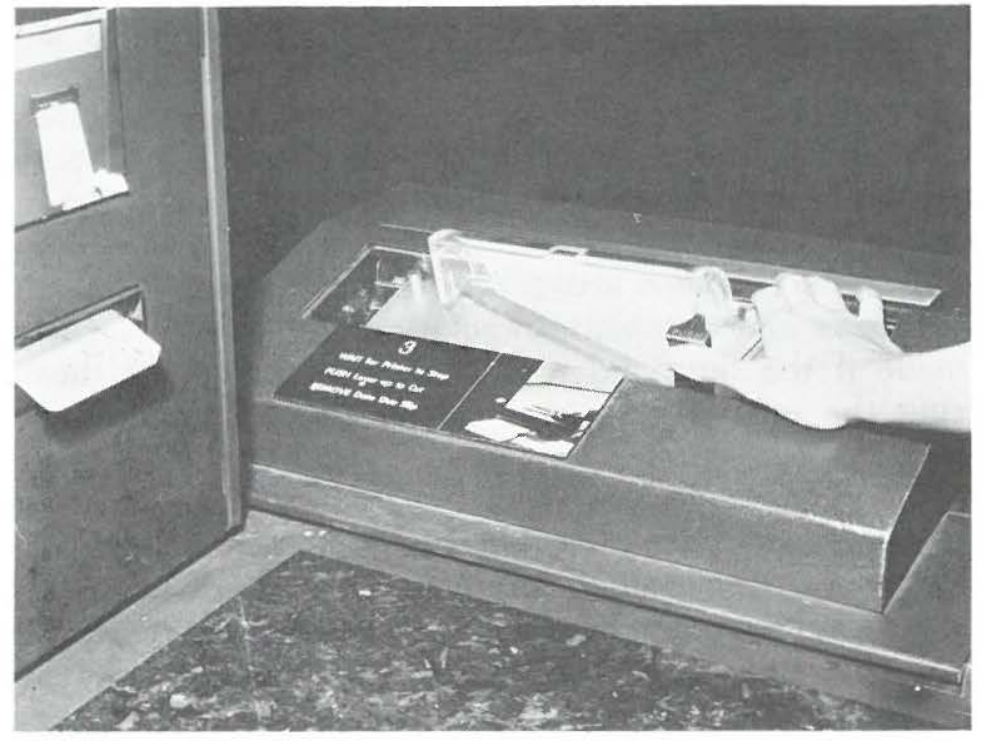

Fig. 2. Specially designed attachment is used to cut off printed

Fig. 3. User inserts date-due slip in book pocket, completing charge procedure.

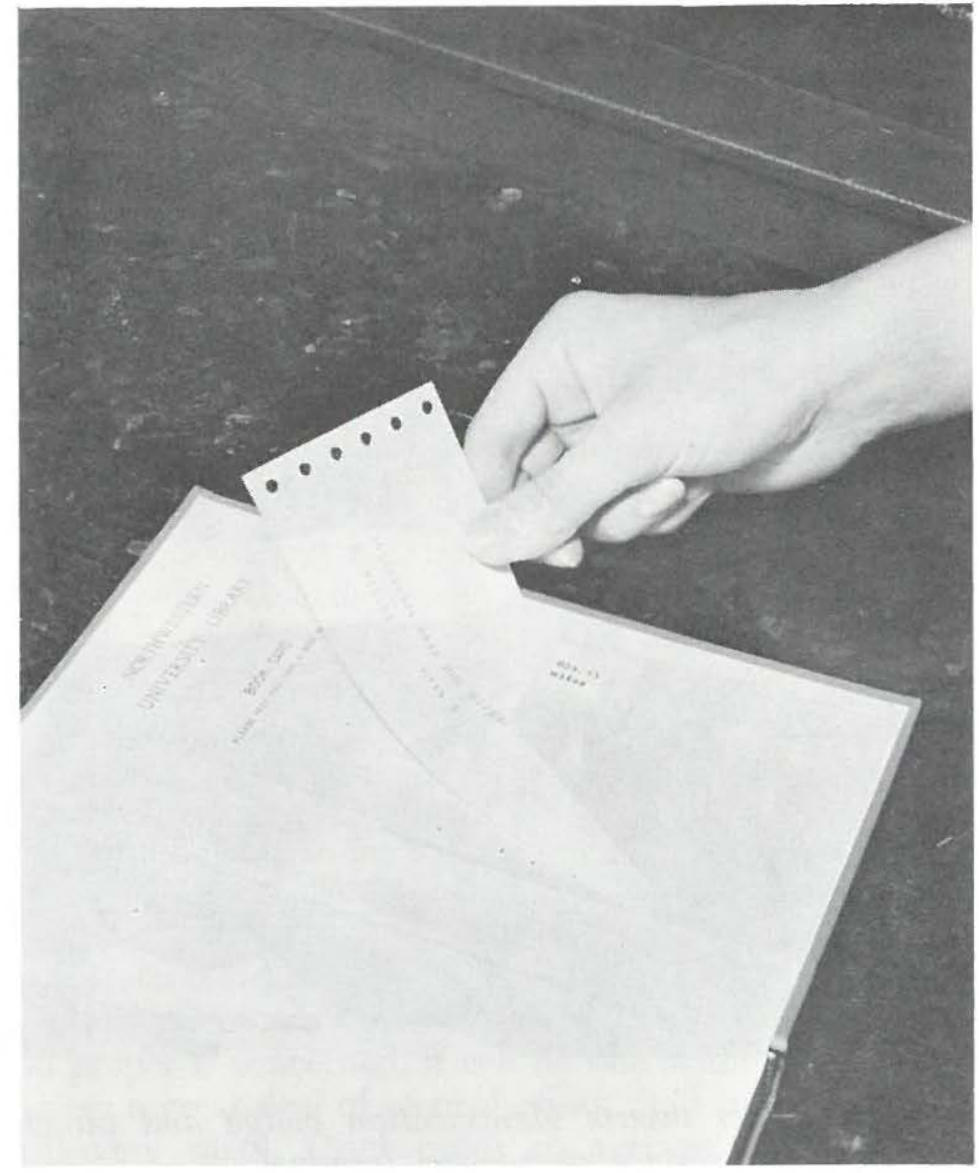


Fig. 4. Terminal at circulation desk has manual entry unit, which can be set to process charges without an identification badge, renewals, or discharges.
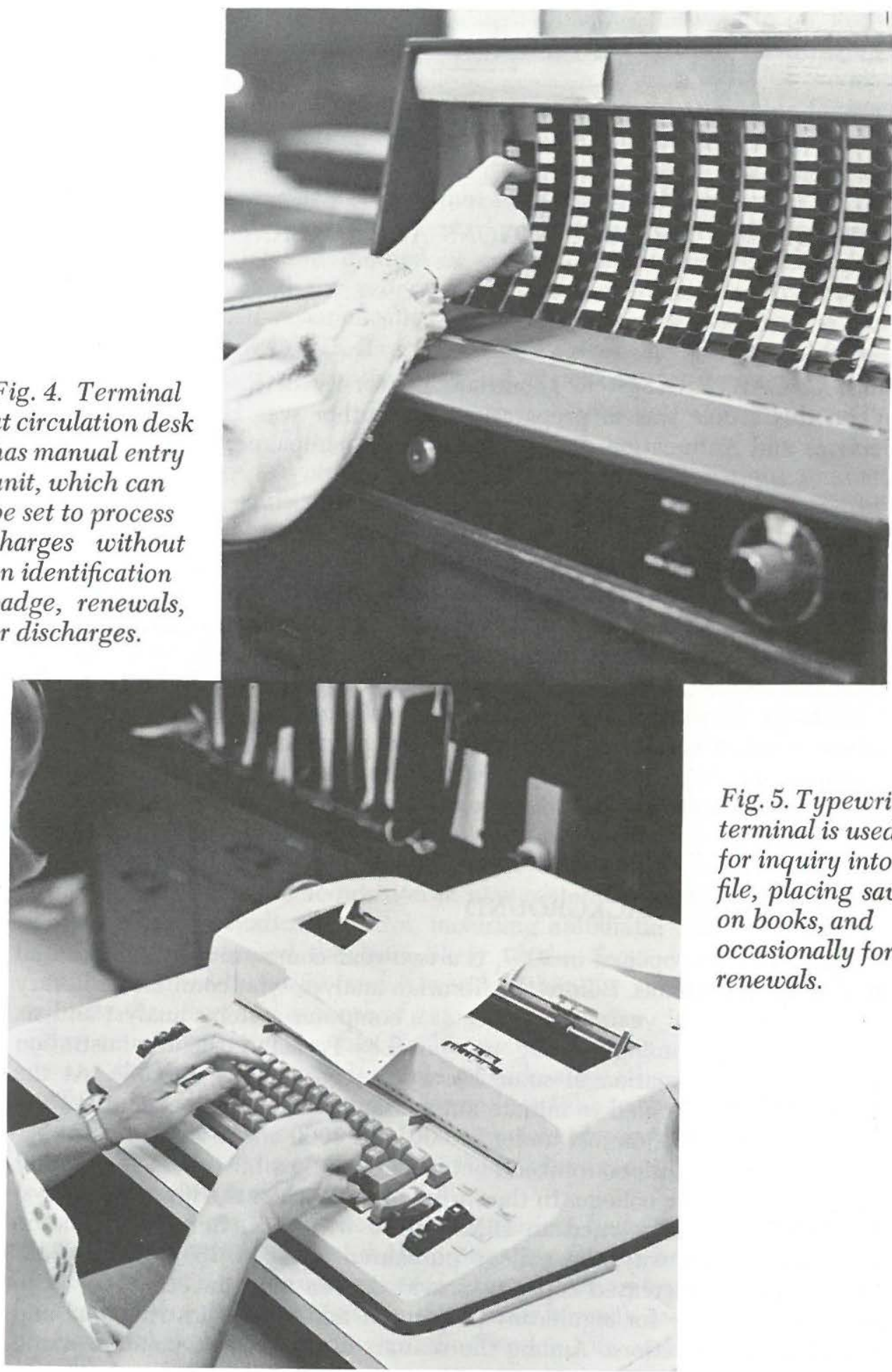

Fig. 5. Typewriter terminal is used for inquiry into file, placing saves on books, and occasionally for renewals. 